\title{
Post liver transplant recurrence in patients with hepatocellular carcinoma: not necessarily the end of the road!
}

\author{
Prashant Bhangui, Sanjay Yadav, AS Soin \\ Medanta Institute of Liver Transplantation and Regenerative Medicine, Medanta-The Medicity, Gurgaon, Delhi NCR 122001, \\ India.
}

Correspondence to: Dr. Prashant Bhangui, Senior Consultant Hepatobiliary and Liver Transplant Surgeon, Medanta Institute of Liver Transplantation and Regenerative Medicine, Medanta-The Medicity, Sector 38, Gurugram, Delhi NCR 122001, India. E-mails: pbhangui@gmail.com; prashant.bhangui@medanta.org

How to cite this article: Bhangui P, Yadav S, Soin AS. Post liver transplant recurrence in patients with hepatocellular carcinoma: not necessarily the end of the road! Hepatoma Res 2020;6:71. http://dx.doi.org/10.20517/2394-5079.2020.67

Received: 14 Jul 2020 First Decision: 24 Aug 2020 Revised: 7 Sep 2020 Accepted: 15 Sep 2020 Published: 12 Oct 2020

Academic Editor: Nobuhisa Akamatsu Copy Editor: Cai-Hong Wang Production Editor: Jing Yu

\begin{abstract}
Aim: We analysed outcomes using multimodality therapy in patients with hepatocellular carcinoma (HCC) recurrence post living donor liver transplantation (LDLT).
\end{abstract}

Methods: Of 2363 LDLT's performed between 2005 to mid 2018, 435 (18.4\%) were for HCC within our expanded selection criteria (absence of extrahepatic disease and vascular invasion, irrespective of tumor size and number). Survival after recurrence, and prognostic factors for these patients were studied.

Results: Of 435 LDLT patients, 51\% had HCC beyond Milan and 43\% beyond UCSF criteria at the time of LDLT. pre-LT AFP > $100 \mathrm{ng} / \mathrm{mL}$ and tumour FDG-18 PET avidity predicted overall survival (OS), whereas pre-LT AFP > $100 \mathrm{ng} / \mathrm{mL}$, UCSF criteria, and FDG-18 PET avidity predicted recurrence-free survival. Hundred patients (23\%) developed HCC recurrence at a median time of 16 months (range 2-108 months) post LDLT. Lungs (53\%), liver $(37 \%)$, and bone (21\%) were the most common sites of recurrence. Ninety-five patients received tyrosine kinase inhibitors (TKI) after recurrence and 62 received mTOR inhibitors (protocol-based after LDLT, or post recurrence). Surgical resection of metastases was performed in 14 patients, 15 received stereotactic body radiotherapy, and 18 underwent ablation (radiofrequency, microwave ablation, transarterial chemoembolisation, or percutaneous ethanol injection). One- and 3-yr OS after recurrence were 57\%, and $24 \%$ respectively, with a maximum post recurrence survival of 7.5 years. $\mathrm{HCC}$ recurrence within one year after $\operatorname{LDLT}(P=0.004, \mathrm{HR}=2.38,95 \% \mathrm{Cl}: 1.325$ -

\footnotetext{
(@) $(0$

(C) The Author(s) 2020. Open Access This article is licensed under a Creative Commons Attribution 4.0 International License (https://creativecommons.org/licenses/by/4.0/), which permits unrestricted use, sharing, adaptation, distribution and reproduction in any medium or format, for any purpose, even commercially, as long as you give appropriate credit to the original author(s) and the source, provide a link to the Creative Commons license, and indicate if changes were made.
}

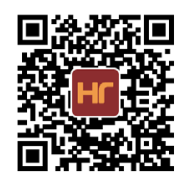


4.276), AFP $>200 \mathrm{ng} / \mathrm{mL}$ at the time of recurrence $(P=0.02, \mathrm{HR}=2.075,95 \% \mathrm{Cl}: 1.121-3.841)$, and recurrence at multiple sites $(P=0.047, \mathrm{HR}=1.831,95 \% \mathrm{Cl}$ : 1.009-3.321) were poor prognostics factors for post recurrence survival. Multimodality management of recurrence using combined medical, surgical, ablative treatments and radiotherapy significantly improved survival compared to the use of TKI's or mTORi's alone, or in combination.

Conclusion: In patients accepted for LDLT beyond the conventional size-number criteria, even after HCC recurrence, an aggressive approach using multimodality therapy, when possible, aids in further prolongation of survival.

Keywords: Living donor liver transplantation, hepatocellular carcinoma recurrence, multimodality treatment, outcomes, prognostic factors

\section{INTRODUCTION}

Liver transplantation (LT) is now accepted as the best curative option for hepatocellular carcinoma (HCC) in patients with decompensated liver disease as it achieves oncological clearance, and also treats the underlying chronic liver disease (CLD) ${ }^{[1]}$. This however holds true when selection of patients for LT adheres to either the conventional Milan ${ }^{[2]}$ and $\mathrm{UCSF}^{[3]}$ criteria, or other expanded criteria ${ }^{[4-9]}$ which have also yielded similar long term outcomes. Over the years, the focus of selection has shifted from size and number of tumours on pre-LT imaging, to tumour biology. Inclusion of tumour markers like alpha fetoprotein (AFP) and des-gamma-carboxy- prothrombin (DGCP), grade of the tumour, and FDG-18 PET scan avidity in the selection criteria, indicates the increased recognition that tumour biology is crucial and dictates long term outcome ${ }^{[10-13]}$. The main determinant of long term outcomes in HCC patients after LT is indeed tumour recurrence, and it continues to be the Achilles heel of this curative strategy. With an expansion of criteria, the chance of recurrence tend to be higher. It is still believed that recurrence leads to early death in most cases, since management of post-LT HCC recurrence to prolong survival remains very challenging. Recurrences frequently occur within the first 2 years after LT, however very late recurrence after a 10 year period have also been reported ${ }^{[14-16]}$. Furthermore, recurrences tend to occur as extrahepatic disease (as high as $71 \%$ ), followed by intrahepatic recurrence alone, and both intra- plus extrahepatic recurrence ${ }^{[17]}$. Given that recurrence more often occurs at multiple sites, treatment of recurrence is even more difficult, and mostly limited to systemic therapy alone. Tumour burden at the time of recurrence is also a major determinant of outcomes (single $v s$. multiple nodules at the time of recurrence). The options available for systemic therapy are few, including tyrosine kinase inhibitors, and the recently introduced checkpoint inhibitors. Results using these systemic agents are far from satisfactory, and they are known to prolong survival only by a few months.

In this study, we analyzed our results in managing patients with HCC recurrence post-LDLT with the use of multimodality treatment including surgical resection, ablative treatment, radiotherapy, modulation of immunosuppression, and systemic agents.

\section{METHODS}

\section{Selection criteria for LT in patients with cirrhosis and HCC}

At our center, we accept medically fit HCC patients for living donor liver transplantation (LDLT) irrespective of tumor size and number, provided they have no extrahepatic disease, or major vascular invasion. Listing for deceased donor liver transplantation is based on the UCSF criteria. Pre-LT recipient evaluation in HCC patients includes a whole body FDG-18 PET scan with triphasic CT angiography abdomen (or dynamic contrast MRI in recipients with borderline renal function), and whole body Tc-99m bone scan to rule out extent of hepatic, as well as extrahepatic spread. Alpha-fetoprotein (AFP) levels are also measured. 


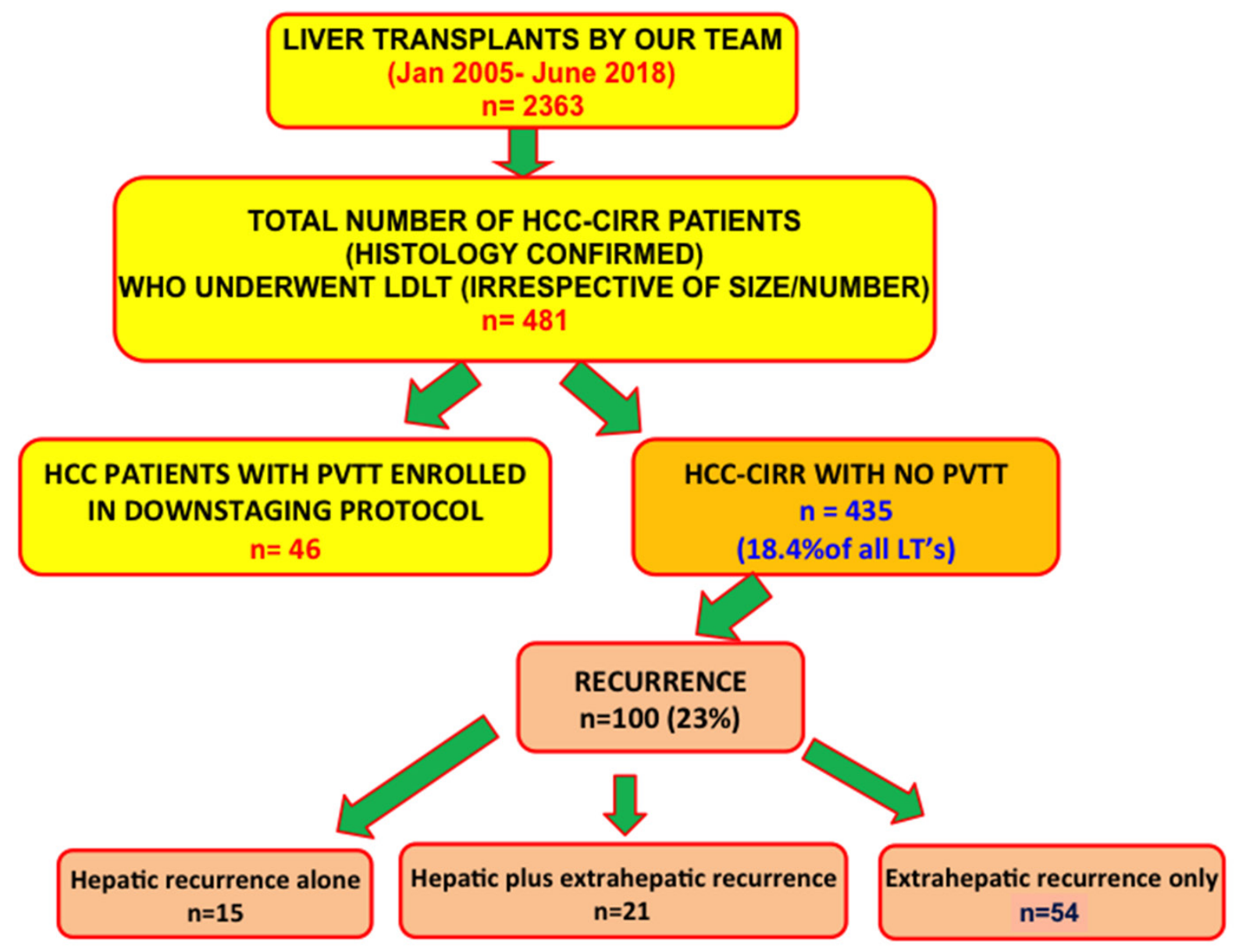

Figure 1. Patient Cohort

\section{Study cohort}

From our prospectively maintained database of 2,363 LDLT's (2005 to mid 2018 so as to have a minimum follow up of 2 years post LDLT at the time of data analysis), we studied outcomes in 435 histologically confirmed (on the explant specimen) cirrhosis and HCC (HCC-cirr) patients (18.4\% of all LDLTs performed during this period). During this period, 481 LDLT's were performed in HCC-cirr patients. Forty-six had segmental or lobar portal vein tumour thrombosis, and underwent downstaging before LDLT as per our Institutional protocol ${ }^{[18]}$. Those 46 patients were excluded from this study. Hundred patients developed recurrence, and their management and outcomes were further analysed [Figure 1].

\section{Post LDLT immunosuppression and follow up}

Post LDLT, patients were maintained on the standard 3 drug immunosuppressive regimen consisting of $\mathrm{CNI}$ inhibitor (Tacrolimus or cyclosporine), mycophenolate mofetil and steroid, the doses of which were slowly tapered, and steroid and mycophenolate were gradually omitted (usually by 6 months and 2 years, respectively). Since 2014, we followed a policy of early switch to mTOR inhibitor based immunosuppression with CNI reduction, 4-6 weeks after LDLT.

In addition to the routine follow up of all transplanted patients, follow up for tumour recurrence in HCCcirr patients included USG and AFP level at 3 months and 6 months, then once every 6 months till 2 years after LT. After this USG and AFP were repeated once annually. MDCT abdomen (or PET-scan if the tumours were initially PET-avid) was done 6 monthly for the first two years after LDLT, and then yearly. 
Symptoms suggestive of metastases such as chest symptoms or bone pains were evaluated as indicated. All cases with suspected recurrence were discussed at a multidisciplinary meeting. Patients with an increased AFP underwent triphasic PET CT scans for radiological confirmation of HCC recurrence; histological confirmation was obtained only where the diagnosis was doubtful.

\section{Management of recurrence}

Different treatment options were discussed in a multidisciplinary team meeting which included surgeons, radiologists, hepatologists, and oncologists. All patients were treated with sorafenib (after 2009), either alone (when other loco regional therapy or surgical resection were not possible), or in combination with surgery/ablation/radiotherapy. Resection was proposed in patients whenever technically feasible, especially in patients with isolated metatases in the lungs [video assisted thoracoscopic surgery (VATS), liver, bone, or scar site. Ablative therapy included transarterial chemoembolisation (TACE) for liver recurrence, or radiofrequency ablation (RFA)] for liver, lung or bone lesions. Stereotactic body radiotherapy was used for bone, lung, or hepatic recurrence in some cases.

\section{Statistical analysis}

Continuous variables are expressed as mean $\pm \mathrm{SD}$ or median (range, IQR) as appropriate. Categorical data are presented as frequency and percentage. For outcomes post LDLT, overall survival (OS) was calculated from the date of transplant to the date of death or last follow up, whereas recurrence-free survival (RFS) was calculated from the date of transplant to the date of first recurrence, or last follow up whichever was earlier. Post-recurrence was calculated from the time of detection of recurrence till death, or last follow up. The Chi-square test was used for categorical variables, and independent $t$-test or ANNOVA for continuous variables. The Kaplan-Meier method was used for survival analysis, and the survival curves were compared by using the log-rank test. Univariate and multivariate analysis of risk factors associated with post recurrence survival was performed using Cox proportional hazard model. A $P$ value of $<0.05$ was considered statistically significant. All statistical analyses were performed using SPSS version 20.0 for Windows statistical software (SPSS Inc., Chicago, IL, USA).

The study was performed in accordance with the Declaration of Helsinki. Since this was a retrospective review and analysis of prospectively maintained data at our Institute, no consent was required for inclusion in this study. However, all patients who had undergone LDLT or any procedure/therapy for recurrence were consented at every stage.

\section{RESULTS}

The overall and recurrence-free 5 year survival in our cohort of 435 patients was $64 \%$, and $70 \%$, respectively [Figure $2 \mathrm{~A}$ and B]. Prognostic factors for OS included pre-LT AFP $>100 \mathrm{ng} / \mathrm{mL}$ and tumour FDG-18 PET avidity. Predictors of recurrence following multivariate analysis included UCSF criteria on imaging, serum AFP level $>100 \mathrm{ng} / \mathrm{mL}$ before LDLT, and tumour FDG-18 PET avidity.

The baseline clinico-pathological characteristics of 100 HCC-cirr patients who developed recurrence post LDLT are summarised in Table 1. The mean age of the studied population was 53 years of which $88 \%$ were males. The most common underlying causes of cirrhosis were HCV (34\%) and HBV (32\%) cirrhosis. The median pre-LDLT AFP was $96 \mathrm{ng} / \mathrm{mL}$ (range 1-11200), and mean was $788 \pm 1985 \mathrm{ng} / \mathrm{mL} ; 64 \%$ of patients had tumours beyond UCSF, and 71\% beyond Milan criteria. 67\% of tumours were FDG-18 PET scan avid. The characteristics in the entire cohort of 435 patients are detailed in Supplementary Table 1.

In the 100 patients with recurrence, the median time to HCC recurrence after LDLT was 16 months (range 2-108 months), mean AFP at recurrence was $80 \pm 11,796 \mathrm{ng} / \mathrm{mL}$ and majority of the recurrences (68\%) were detected within first two years after LDLT. At the time of diagnosis, most recurrences were extrahepatic 


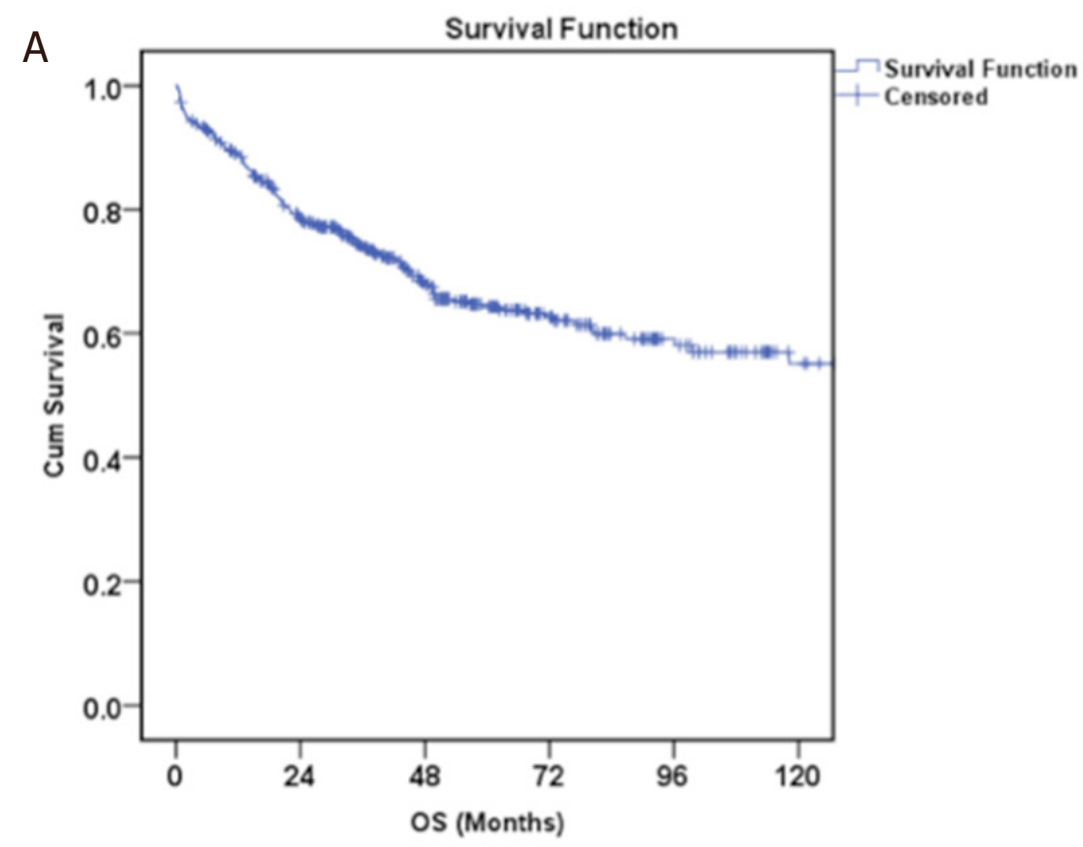

\begin{tabular}{|l|c|c|c|c|c|}
\hline $\begin{array}{l}\text { No. of pts exposed at } \\
\text { different time points }\end{array}$ & 0 years & 1 year & 3 years & 5 years & 10 years \\
\cline { 2 - 5 } & 435 & 376 & 266 & 167 & 60 \\
\hline Overall Survival & & $89 \%$ & $74 \%$ & $64 \%$ & $55 \%$ \\
\hline
\end{tabular}

\section{B}

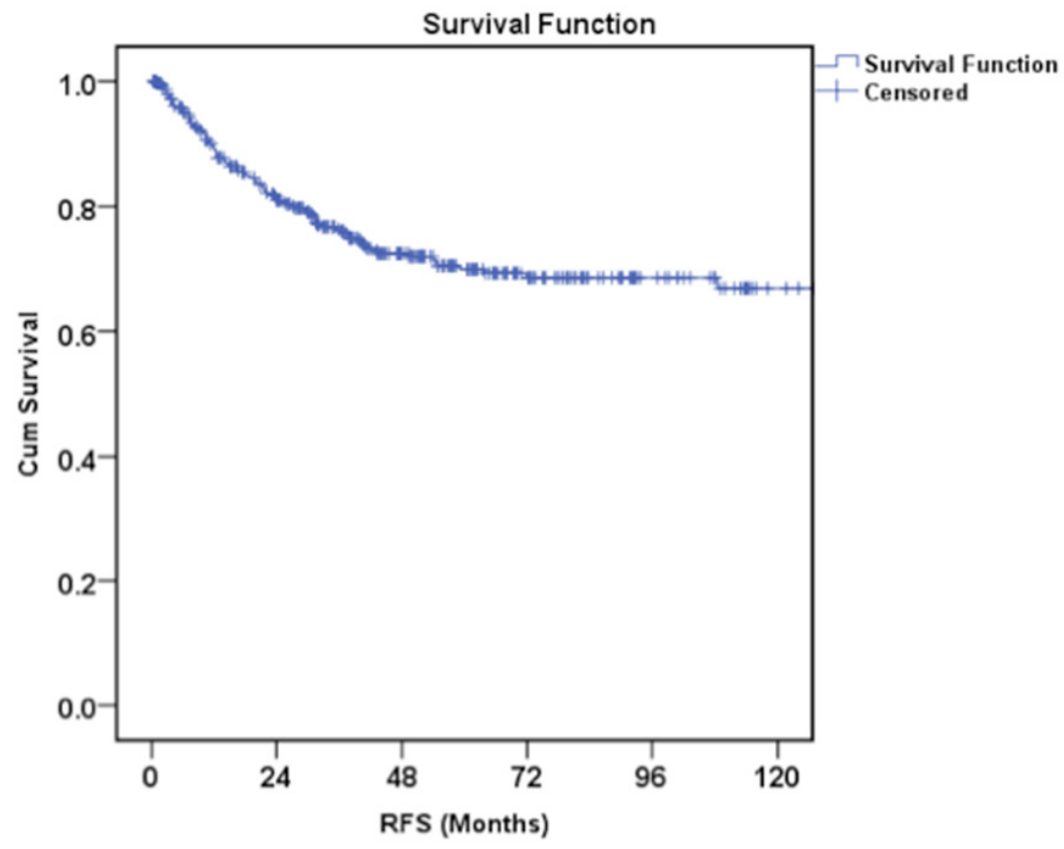

\begin{tabular}{|l|c|c|c|c|c|}
\hline $\begin{array}{l}\text { No. of pts exposed at } \\
\text { different time points }\end{array}$ & 0 years & 1 year & 3 years & 5 years & 10 years \\
\hline & 435 & 376 & 266 & 167 & 60 \\
\hline Recurrence-free Survival & & $89 \%$ & $76 \%$ & $70 \%$ & $67 \%$ \\
\hline
\end{tabular}

Figure 2. Overall survival (A) and recurrence-free survival (B) in our cohort of 435 patients with hepatocellular carcinoma who underwent living donor liver transplantation 
Table 1. Patient demographics and tumour characteristics in 100 patients with HCC recurrence post LDLT

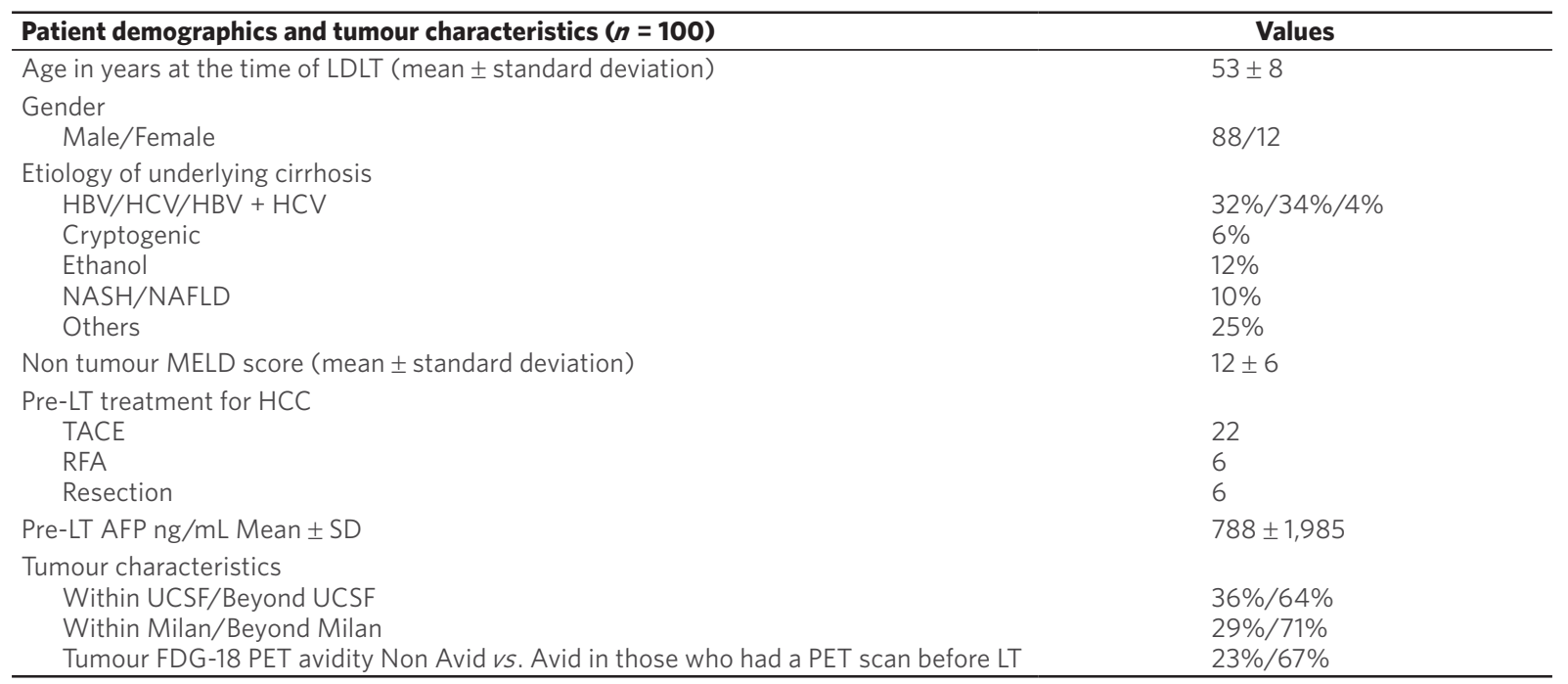

HCC: hepatocellular carcinoma; HBV: hepatitis B virus; HCV: hepatitis C virus; NASH: non alcoholic steatohepatitis; NAFLD: non alcoholic fatty liver disease; MELD: Model for End Stage Liver Disease; TACE: transarterial chemoembolization; RFA: radiofrequency ablation; AFP: alpha feto-protein; UCSF: University of California, San Francisco; FDG-18 PET: 18-fluoro deoxy-glucose positron emission tomography; LT: liver transplantation

( $n=54 ; 54 \%)$, liver only recurrence was seen in 15 patients, and in 21 patients, recurrence occurred in the liver as well as extrahepatic sites. Thirty-six patients presented with HCC recurrence at more than one site and the three most common sites of disease recurrence were lungs (53\%), liver (37\%), and bone (21\%). Thirty-two percent of patients had a single nodule recurrence, whereas $68 \%$ of patients presented with two or more tumour nodules (at one or multiple sites) when they recurred [Table 2].

One patient developed an abdominal wall squamous cell carcinoma post LDLT and subsequently underwent excision. Two other HCC patients (in the overall cohort of 435 patients) developed de novo malignancies during follow up (one patient had an inflammatory myofibroblastic tumour of the colon, and another developed a brain cancer).

\section{Management of HCC recurrence}

Ninety five patients with recurrence were put on sorafenib of which in 20 patients dose adjustment was required due to adverse effects. mTOR inhibitors were used in 62 patients. In 38 patients, they were started "de principe" within 6 months of LDLT, as our protocol from 2012 onwards included switch to mTORI and mycophenolate based immunosuppression with CNI reduction early after LDLT. The other 24 patients were switched over to mTORi's later, either pre emptively (11 patients), or after developing recurrence (13 patients). All patients except one received Sirolimus (1 patient received Everolimus). Thirty-two patients received tyrosine kinase inhibitors (TKI's) alone, and 36 received both TKI's and mTORi's [Table 2].

Surgical excision of lung metastases was performed using VATS in 5 patients, and limited hepatectomy was performed for liver recurrence in 3 patients. Scar site excision $(n=3)$, laminectomy, mediastinal tumour excision, and supraadrenal metastatectomy (one each), were the other surgical procedures performed. Fifteen patients received stereotactic radiotherapy (for bone/lung/liver/soft tissue lesions), 10 underwent RFA or microwave ablation (MWA) of liver/lungs/bone metastases, 5 underwent TACE for liver lesions, and 3 had percutaneous ethanol injection in metastatic lymph nodes [Table 2].

Thirty-two patients received tyrosine kinase inhibitors with/without mTORis and other modalities (surgery and/or ablative therapy and/or radiotherapy). 
Table 2. Characteristics of tumour recurrence and treatment modalities

\begin{tabular}{|c|c|}
\hline Characteristics $(n=100)$ & Values \\
\hline $\begin{array}{l}\text { Time to recurrence after LDLT } \\
\text { Median (range) }\end{array}$ & $\begin{array}{l}16 \text { months } \\
\text { (2-108 months) }\end{array}$ \\
\hline AFP at the time of recurrence $(\mathrm{ng} / \mathrm{mL})$ Mean \pm SD & $80 \pm 11,796$ \\
\hline \multicolumn{2}{|l|}{ Site of tumour recurrence (number of patients) } \\
\hline Lungs & 53 \\
\hline Liver & 37 \\
\hline Bone & 21 \\
\hline Lymph nodes & 7 \\
\hline Brain & 2 \\
\hline Scar site & 2 \\
\hline More than one site of recurrence & 36 \\
\hline \multicolumn{2}{|l|}{ Treatment for recurrence } \\
\hline Kinase inhibitors alone (Sorafenib, Regorafenib, Lenvatinib) & 32 patients \\
\hline Kinase inhibitors with mTORi's (sirolimus, everolimus) only & 36 patients \\
\hline Medical (Kinase inhibitors with/without mTORi's) plus other modalities (surgery, radiotherapy, ablation) & 32 patients \\
\hline \multicolumn{2}{|l|}{ Other modalities used in addition to kinase inhibitors and mTORi's to treat metastases } \\
\hline Radiotherapy & 15 \\
\hline TACE for liver metastases & 5 \\
\hline VATS for lung metastases & 5 \\
\hline Surgical resection of metastases (liver, scar site, mediastinal metastases, laminectomy, supra adrenal metastases) & 9 \\
\hline Percutaneous ethanol injection in lymph node & 3 \\
\hline Radiofrequency ablation and microwave ablation for liver, lung, or bone metastases & 10 \\
\hline More than 1 modality used in one patient & 11 \\
\hline
\end{tabular}

LDLT: living donor liver transplantation; mTORi: mammalian target of rapamycin inhibitor; TACE: transarterial chemoembolization; VATS: video assisted thoracoscopic surgery

When we compared the tumour characteristics at the time of recurrence between the three treatment groups, we found that there was no statistically significant difference in AFP levels, occurrence of metastases at single $v s$. multiple sites, single $v s$. multiple nodules at recurrence, or intrahepatic recurrence only vs. intrahepatic and extrahepatic recurrence [Supplementary Table 2]. However, on post hoc analysis we did find that more patients in the Kinase inhibitor + mToR inhibitor group had HCC recurrence within 1 year of LDLT $(P=0.05)$, and had multiple nodules at the time of recurrence ( $v s$. single nodule, $P=0.04)$ as compared to the combined therapy group.

\section{Survival post recurrence}

One-year, 2-year, and 3-year post recurrence survival were 57\%, 31\%, and 24\%, respectively, with a median survival of 12 months (IQR 4-24 months) [Figure 3]. The maximum post recurrence survival was 88 months ( $71 / 2$ years), and the longest survivor still alive is 77 months post recurrence.

With regards to predictors of survival after recurrence, HCC recurrence within one year after LDLT ( $P$ $=0.004, \mathrm{HR}=2.38,95 \% \mathrm{CI}: 1.325-4.276), \mathrm{AFP}>200 \mathrm{ng} / \mathrm{mL}$ at the time of recurrence $(P=0.02, \mathrm{HR}=2.075$, 95\%CI: 1.121-3.841), and recurrence at multiple sites $(P=0.047, \mathrm{HR}=1.831,95 \% \mathrm{CI}: 1.009-3.321)$, were poor prognostics factors for post recurrence survival [Table 3].

Post recurrence survival rates in the tyrosine kinase inhibitor only group (1-year, 3-year OS of 38\% and $15 \%$ ), as well as the tyrosine kinase with mTORi group (1-year, 3-year OS of 56\% and 19\%) were significantly inferior to those who received multimodality treatment using combined medical and surgical/ ablative/radiotherapy (1-year, 3-year OS of 77\% and 39\%); $P=0.017$ [Figure 4].

\section{DISCUSSION}

Post- transplant HCC recurrence is seen in $10 \%-20 \%$ of the patients and this has remained stable over the years, despite repeated efforts to refine the selection criteria for transplant to achieve best outcomes ${ }^{[6]}$. This is much higher when the selection criteria are expanded, especially in the LDLT setting. A 2015 systematic 


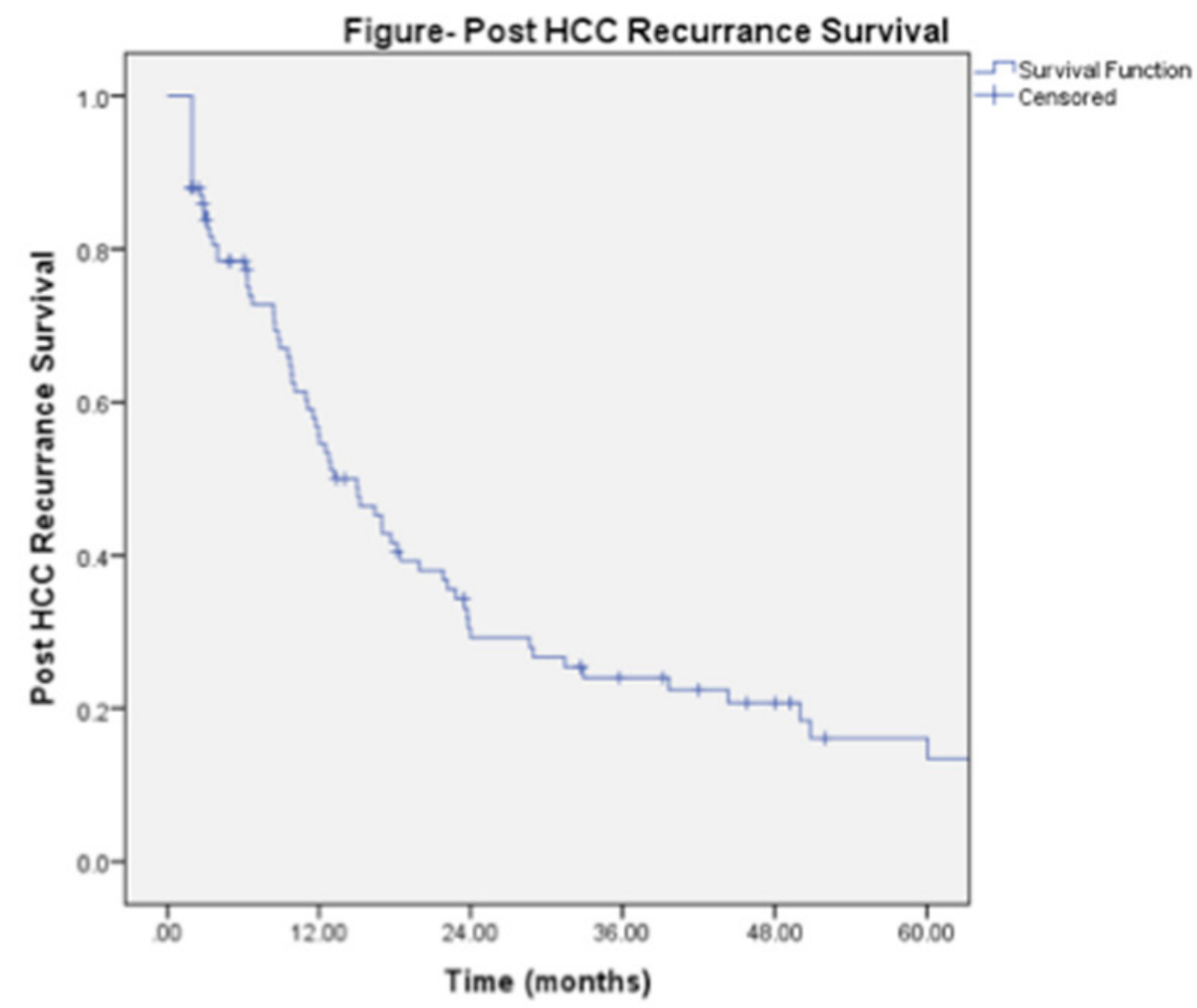

\section{No. of pts exposed at different time points}

1 year

$57 \%$
2 years

$31 \%$
3 years

$24 \%$
5 years

$17 \%$

Figure 3. Overall survival post hepatocellular carcinoma recurrence in 100 patients

Table 3. Cox regression analysis for survival post HCC recurrence

\begin{tabular}{|c|c|c|c|c|c|c|}
\hline \multirow{2}{*}{ Parameters } & \multicolumn{3}{|c|}{ Univariate analysis } & \multicolumn{3}{|c|}{ Multivariate analysis } \\
\hline & Hazard ratio & $95 \% \mathrm{Cl}$ & $P$ value & Hazard ratio & $95 \% \mathrm{Cl}$ & $P$ value \\
\hline Age at the time of recurrence & 1.02 & $0.98-1.05$ & 0.34 & & & \\
\hline Gender - Male & 0.90 & $0.46-1.78$ & 0.77 & & & \\
\hline $\begin{array}{l}\text { HCC within vs. outside UCSF criteria at the } \\
\text { time of LDLT }\end{array}$ & 1.06 & $0.66-1.70$ & 082 & & & \\
\hline $\begin{array}{l}\text { Type of recurrence: recurrence at single } v s \text {. } \\
\text { multiple sites }\end{array}$ & 1.70 & $1.06-2.73$ & 0.029 & 1.831 & $1.009-3.321$ & 0.047 \\
\hline $\begin{array}{l}\text { Tumour burden: single nodule vs. multiple } \\
\text { nodules }\end{array}$ & 2.23 & $1.13-4.40$ & 0.022 & 1.462 & $0.719-2.970$ & 0.294 \\
\hline $\begin{array}{l}\text { Intrahepatic only vs. extrahepatic or } \\
\text { Intrahepatic plus extrahepatic metastases }\end{array}$ & 0.58 & $0.29-1.13$ & 0.11 & & & \\
\hline $\begin{array}{l}\text { Alpha fetoprotein at the time of recurrence } \\
\text { AFP }<200 \mathrm{vs} .>200 \mathrm{ng} / \mathrm{mL}\end{array}$ & 2.59 & $1.42-4.71$ & 0.002 & 2.075 & $1.121-3.841$ & 0.020 \\
\hline $\begin{array}{l}\text { Time to HCC recurrence: }>1 \text { year after LDLT } \\
\text { vs. within } 1 \text { year of LDLT }\end{array}$ & 2.49 & $1.56-3.98$ & 0.001 & 2.381 & $1.325-4.276$ & 0.004 \\
\hline
\end{tabular}

HCC: hepatocellular carcinoma; LDLT: living donor liver transplantation; UCSF: University of California, San Francisco; mTORi: mammalian target of rapamycin inhibitor 


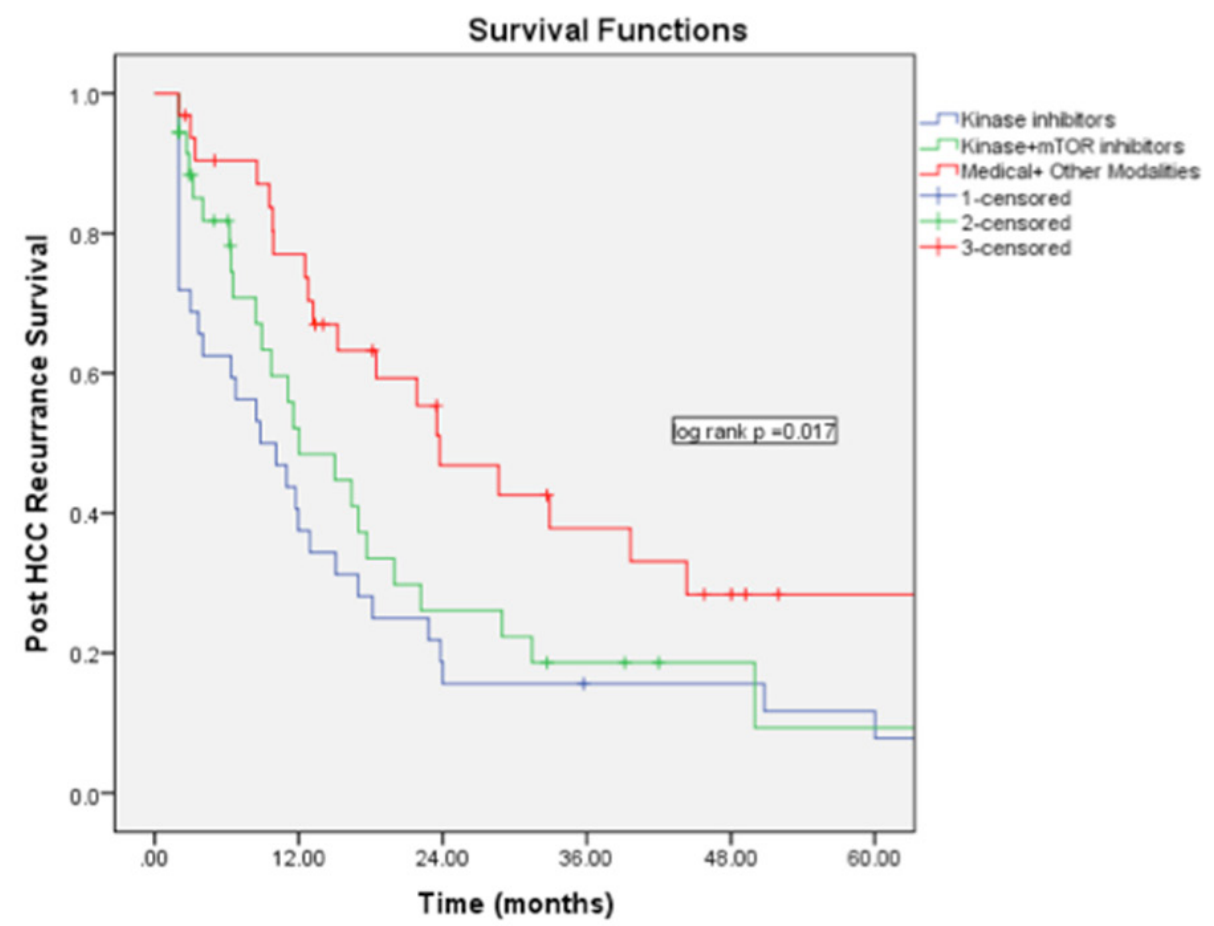

\begin{tabular}{|c|c|c|c|c|}
\hline Overall Survival & 1 year & 2 years & 3 years & 5 years \\
\hline Tyrosine kinase inhibitors alone & $38 \%$ & $19 \%$ & $15 \%$ & $12 \%$ \\
\hline Tyrosine kinase and mTOR inhibitors & $56 \%$ & $28 \%$ & $19 \%$ & $10 \%$ \\
\hline Medical plus other treatment modalities & $77 \%$ & $48 \%$ & $39 \%$ & $28 \%$ \\
\hline
\end{tabular}

Figure 4. Comparative post-recurrence survival in patients with hepatocellular carcinoma recurrence based on therapeutic modalities used

review including a heterogeneous group of 61 studies demonstrated a mean recurrence rate of $16 \%$, and mean time from transplant to HCC recurrence of 13 months (range 2-132 months) ${ }^{[19]}$. The median time to recurrence in our series was 16 months (IQR 8-29 months). As centers worldwide transplant patients with HCC beyond Milan criteria, the magnitude of HCC recurrence may be larger than proposed by these estimates $^{[20]}$. On the other hand, in patients slightly beyond conventional criteria, LT remains the best treatment option, since ablative or systemic therapy are often not possible due to deranged liver function, and LT is the best chance for oncological cure.

Post LT HCC recurrence is the key determinant of survival, and managing patients with recurrence continues to be a major challenge, as none of the treatment options guarantee long term survival. Predominant extrahepatic recurrence, and recurrence at multiple sites, are two main issues that make management difficult.

Early HCC recurrence (within the first year of LT), usually portends worse prognosis ${ }^{[21,22]}$. Our findings were similar, with recurrence within the first year predicting worse survival. Early recurrence could occur due to non-detectable extrahepatic metastases that may be present before LT, or due to circulating HCC tumour cells engrafting and growing in a target organ after LT. A strict post-LT surveillance protocol during the 1-2 year period post-LT (which covers most recurrences), could help in early detection when metastases are amenable to curative treatment, especially if they are single and resectable. Surveillance and staging should include regular imaging of lungs, bone and liver graft (most common sites of recurrences), 
and should be performed using modalities that are highly sensitive and specific (whole body FDG-18 PET scan with triphasic CT angiography abdomen, or contrast computed tomography abdomen and chest with bone scan). In our study, we found that $68 \%$ of recurrences occurred within two years following LT, which is in accordance with other studies (median time of recurrence 7-36 months) ${ }^{[23-27]}$.

Sorafenib is known to confer some survival benefit in patients with disseminated recurrence (median survival of 12 months) ${ }^{[28-33]}$, but is also associated with some drug limiting side effects. Combined with mTOR inhibitors, the synergistic effect shows a trend towards better tumour response. High dose CNI exposure has been shown to be a risk factor for HCC recurrence. Hence, an mTORi based immunosuppression strategy with reduced CNI has been proposed in HCC patients post LT to reduce recurrence $^{[34]}$ and improve survival benefit as demonstrated in a meta analysis ${ }^{[35]}$. Sirolimus is generally well tolerated. Recently, studies using everolimus in both the deceased donor and living donor LT scenario have shown a tendency towards lower recurrence ${ }^{[36]}$. A recent meta analysis comparing everolimus and sirolimus ${ }^{[37]}$ showed lower recurrence rates in patients on everolimus compared to those on sirolimus or calcineurin inhibitors. However, everolimus-treated recipients had a shorter follow-up time and fewer advanced tumours in the above study. Though data on mTOR inhibitor therapy for established recurrence after liver transplantation remain scarce, a combination of either sirolimus or everolimus with reduceddose tacrolimus may prove beneficial in addition to sorafenib ${ }^{[36,38,39]}$. Our study showed that recurrence at multiple sites was a poor prognostic factor for survival post recurrence. In patients with recurrence at multiple sites where no form of directed therapy is possible, combining TKI's with mTORi's, with initial reduction in CNI dose and then stopping it, may prolong survival. In patients with recurrence who are not already on mTORi's, therapy is initiated (initially at a dose of $0.75 \mathrm{mg}$ BD Everolimus or $1 \mathrm{mg}$ OD of Sirolimus) and maintained with trough levels of 3-5 ng/mL. CNI's doses are gradually reduced and then omitted. If required, the patient is additionally maintained on mycophenolate mofetil in a low dose and titrated based on liver function.

We tried to analyze the change in AFP levels (response to treatment) in our cohort of patients. We looked at the initial AFP (pre-LDLT) level, AFP at recurrence, and evolution with treatment. AFP was high (> $50 \mathrm{ng} / \mathrm{mL}$ in 57 patients, $>100 \mathrm{ng} / \mathrm{mL}$ in 47 patients) in only $50-60 \%$ of patients at the time of LDLT (AFP secretors) itself. Of the 48 patients with AFP $>100 \mathrm{ng} / \mathrm{mL}$ at the time of LDLT, only 20 patients presented with high AFP levels at the time of recurrence, and only 12 patients had AFP levels that were similar to or higher than those pre LDLT. This could probably be due to early detection of recurrences using a stringent follow up protocol. Due to this low number of patients with high AFP levels at the time of recurrence, we could not draw any definite conclusions with respect to change in AFP levels post treatment. Patients who had high AFP levels were those who had recurrence at multiple sites. Patients whose AFP levels responded (decreased) to treatment had a longer survival, and most had been treated with a combination of Sorafenib and Sirolimus.

In patients who progress on sorafenib, regorafenib may be used as a second-line agent ${ }^{[40]}$. The utility of checkpoint inhibitors as immunotherapy in transplant recipients may appear promising, but also poses challenges due to the potentially increased risk of allograft rejection and graft loss ${ }^{[4]}$.

Surgical resection or ablation of HCC recurrence (as opposed to systemic or palliative therapy alone) has been shown to be an independent predictor of long-term survival if recurrence is isolated to a single organ, whether it is in the liver or an extrahepatic site ${ }^{[14,22-24,42-44]}$. Post-LT HCC recurrences develop in non-cirrhotic livers without portal hypertension, thus qualifying most patients for surgery. Most studies have shown that resection is safe and significantly prolongs survival after HCC recurrence as compared to palliative treatment. In a recent study, Fernandez-Sevilla et al. ${ }^{[2]}$ reported a median survival of 35 months (vs. 15 months) in patients with resection ( $v s$. non resection) of intra- and extrahepatic recurrences. Actual 
benefit following surgery in patients with HCC recurrence post LT could of course be challenged, as only some patients with a limited disease burden may be amenable to resection.

Lung is the most common site of recurrence, probably owing to proximity to the liver at the time of hepatectomy, and the lymphatic drainage ${ }^{[45]}$. In our study, we also observed that lungs were the most frequent site of HCC recurrence. Resection of pulmonary metastases is often not attempted owing to their multiplicity, frequent multiorgan involvement, and unclear impact on survival. However, some centers have reported good outcomes of pulmonary metastases resection (PMR) in patients treated by liver resection or ablative procedures for the liver recurrence ${ }^{[24,46,47]}$. In a large series of pulmonary metastatectomy cases post LT, Hwang et al. ${ }^{[48]}$ showed that those patients who were selected for surgery based on the feasibility of complete resection and sufficient pulmonary function after surgery, the 5-year survival rate was significantly better. A large Italian multicenter study ${ }^{[45]}$ found that pulmonary metastatectomy with a low complication rate was feasible in patients who were judged operable when they developed pulmonary metastasis as the first metastasis after LT for HCC. One year, 3-yr, and 5-yr cumulative overall survival rates of $100 \%, 66 \%$, and $43 \%$, respectively, were reported in this study, with a median OS of 51 months. They selected patients with lung only metastasis, and a good liver function for surgery. Repeat metastatectomy for recurrence after the first surgery has also been proposed ${ }^{[49-53]}$. In the 5 patients who underwent VATS resection of pulmonary metastases in our series, the median survival post recurrence was 18 months (range 10-52 months). When pulmonary metastatectomy is precluded by inadequate lung function, SBRT is considered an alternative $e^{[54]}$.

Ablative therapy in the form of RFA or $\mathrm{MWA}^{[55]}$, $\mathrm{TACE}^{[56]}$, and TARE using Yttrium-90 microspheres (Y-90) for unresectable intrahepatic HCC recurrence ${ }^{[57]}$, have also occasionally shown good results. A retrospective cohort study compared results in 15 patients who were treated with surgery $v s .11$ who underwent RFA for intrahepatic recurrence ${ }^{[58]}$. A similar 3-year $(51 \%$ vs. $51 \%, P=0.88)$ and 5 -year $(35 \%$ vs. $28 \%, P=0.88)$ overall survival was reported in the two groups. Zhou et al. ${ }^{[59]}$ prospectively compared TACE $v s$. systemic therapy in patients with unresectable intrahepatic recurrence. Survival benefits were achieved in the TACE arm $(P=0.013)$, indicating that regional control could have contributed to the improvement in overall survival.

Ablative treatment modalities are usually safe and well tolerated, and may be repeated multiple times or combined in a multimodality approach. Some also propose that early intrahepatic HCC recurrences may be better "tested" by a locoregional treatment, prior to performing a resection, provided no further disease appears in the mean time ${ }^{[60]}$.

Use of non-invasive radiotherapy such as SBRT is also effective for local control of pulmonary and skeletal oligo-recurrences. Similarly, focused ablation of intrahepatic HCC recurrence spares the adjacent normal liver parenchyma. A higher dose of radiation is delivered while the risk of collateral damage is minimized ${ }^{[61]}$. An abbreviated duration of treatment with SBRT (usually completed in 1-5 fractions) compared to the 10-20 days for conventional radiotherapy (during which systemic therapy is usually deferred) is an added advantage. It is now also established in pre-clinical models that stereotactic radiation may up regulate antitumour immunity ${ }^{[62-64]}$.

Results of our analysis also emphasized the utility of multimodality treatment. including systemic therapy combined with surgery/ablation/radiotherapy. In 32 patients undergoing resection or ablative treatment in addition to systemic therapy, the post recurrence survival was superior to systemic therapy alone. This is in line with the limited studies that have been published on this topic ${ }^{[65-67]}$. It is however also true that resection or ablation is not possible in all patients with recurrence, especially in those with recurrence at multiple sites or multiple nodules at the time of recurrence. One may argue that due to this reason, 
the results are biased towards the multimodality treatment group. We recommend surgical resection of isolated metastasis (either in extra hepatic or intrahepatic location) in carefully selected patients with good functional status. If resection is not possible, ablative therapy and SBRT should be used especially in liver, lung or bone metastases. Systemic therapy with Kinase inhibitors (mainly sorafenib) is advisable in all patients. Furthermore, combination therapy with mTOR inhibitors (sirolimus, everolimus) in order to reduce CNI doses, may have some benefit over kinase inhibitors alone, as seen in our study.

In conclusion, multimodality treatment for post LT HCC recurrence has shown to further improve survival rates, which calls for an aggressive approach while formulating a treatment regime for these patients.

\section{DECLARATIONS}

\section{Acknowledgments}

We would like to acknowledge the core members of our multidisciplinary team in the Institute including Amit Rastogi, Thiagarajan S, Rohan Chaudhary, Kamal Yadav, Ankur Gupta (all from Department of Surgery), Sanjiv Saigal, Neeraj Saraf, Narendra Choudhary (all from Department of Hepatology), S S Baijal (Department of Interventional Radiology), Tejinder Kataria (Department of Radiation Oncology), Dheeraj Gautam (Department of Pathology) who were actively involved in the management of all these patients during and post liver transplantation, and after recurrence.

\section{Authors' contributions}

Made substantial contributions to conception and design of the study and performed data analysis and interpretation: Bhangui P, Yadav S

Drafted the manuscript and substantively revised it: Bhangui P, Yadav S, Soin AS

\section{Availability of data and materials}

The authors can provide data if required, this data however is a part of the entire HCC database of the Institute based on which a manuscript is currently undergoing review in another Journal.

\section{Financial support and sponsorship}

None.

\section{Conflicts of interest}

All authors declared that there are no conflicts of interest.

\section{Ethical approval and consent to participate}

Not applicable.

\section{Consent for publication}

Not applicable.

\section{Copyright}

(c) The Author(s) 2020.

\section{REFERENCES}

1. European Association for the Study of the Liver. Corrigendum to "EASL Clinical Practice Guidelines: management of hepatocellular carcinoma". J Hepatol 2018;69:182-236.

2. Mazzaferro V, Regalia E, Doci R, Andreola S, Pulvirenti A, et al. Liver transplantation for the treatment of small hepatocellular carcinomas in patients with cirrhosis. N Engl J Med 1996;334:693-9.

3. Yao FY, Xiao L, Bass NM, Kerlan R, Ascher NL, et al. Liver transplantation for hepatocellular carcinoma: validation of the UCSF expanded criteria based on pre-operative imaging. Am J Transpl 2007;7:2587-96. 
4. Herrero JI, Sangro B, Quiroga J, Pardo F, Herraiz M, et al. Influence of tumor characteristics on the outcome of liver transplantation among patients with liver cirrhosis and hepatocellular carcinoma. Liver Transpl 2001;7:631-6.

5. Duffy JP, Vardanian A, Benjamin E, Watson M, Farmer DG, et al. Liver transplantation criteria for hepatocellular carcinoma should be expanded. A 22-year experience with 467 patients at UCLA. Ann Surg 2007;246:502-11.

6. Mazzaferro V, Llovet JM, Miceli R, Bhoori S, Schiavo M, et al. Predicting survival after liver transplantation in patients with hepatocellular carcinoma beyond the Milan criteria: a retrospective, exploratory analysis. Lancet Oncol 2009;10:35-43.

7. D'Amico F, Schwartz M, Vitale A, Tabrizian P, Roayaie S, et al. Predicting recurrence after liver transplantation in patients with hepatocellular carcinoma exceeding the up-to-seven criteria. Liver Transpl 2009;15:1278-87.

8. Sugawara Y, Tamura S, Makuuchi M. Living donor liver transplantation for hepatocellular carcinoma: Tokyo University series. Dig Dis 2007;25:310-2.

9. Lee SG, Hwang S, Moon DB, Ahn CS, Kim KH, et al. Expanded indication criteria of living donor liver transplantation for hepatocellular carcinoma at one large-volume center. Liver Transpl 2008;14:935-45.

10. Duvoux C, Roudot-Thoraval F, Decaens T, Pessione F, Badran H, et al; Liver Transplantation French Study Group. Liver transplantation for hepatocellular carcinoma: a model including $\alpha$-fetoprotein improves the performance of Milan criteria. Gastroenterology 2012;143:986-94.

11. Kaido T, Ogawa K, Mori A, Fujimoto Y, Ito T, et al. Usefulness of the Kyoto criteria as expanded selection criteria for liver transplantation for hepatocellular carcinoma. Surgery 2013;154:1053-60.

12. Taketomi A, Sanefuji K, Soejima Y, Yoshizumi T, Uchiyama H, et al. Impact of des-gamma-carboxy prothrombin and tumor size on the recurrence of hepatocellular carcinoma after living donor liver transplantation. Transplantation 2009;87:531-7.

13. Ito T, Takada Y, Ueda M, Haga H, Maetani Y, et al. Expansion of selection criteria for patients with hepatocellular carcinoma in living donor liver transplantation. Liver Transpl 2007;13:1637-44.

14. Clavien PA, Lesurtel M, Bossuyt PM, Gores GJ, Langer B, et al. Recommendations for liver transplantation for hepatocellular carcinoma: an international consensus conference report. Lancet Oncol 2012;13:e11-22.

15. Alshahrani AA, Ha SM, Hwang S, Ahn CS, Kim KH, et al. Clinical features and surveillance of very late hepatocellular carcinoma recurrence after liver transplantation. Ann Transplant 2018;23:659-65.

16. Chok KS, Chan SC, Cheung TT, Chan AC, Fan ST, et al. Late recurrence of hepatocellular carcinoma after liver transplantation. World J Surg 2011;35:2058-62.

17. Foerster F, Hoppe-Lotichius M, Vollmar J, Marquardt JU, Weinmann A, et al. Long-term observation of hepatocellular carcinoma recurrence after liver transplantation at a European transplantation centre. United European Gastroenterol J 2019;7:838-49.

18. Soin AS, Bhangui P, Kataria T, Baijal SS, Piplani T, et al. Experience with LDLT in patients with hepatocellular carcinoma and portal vein tumor thrombosis postdownstaging. Transplantation 2020; doi: 10.1097/TP.0000000000003162.

19. de'Angelis N, Landi F, Carra MC, Azoulay D. Managements of recurrent hepatocellular carcinoma after liver transplantation: a systematic review. World J Gastroenterol 2015;21:11185-98.

20. Mazzaferro V, Sposito C, Zhou J, Pinna AD, De Carlis L, et al. Metroticket 2.0 model for analysis of competing risks of death after liver transplantation for hepatocellular carcinoma. Gastroenterology 2018;154:128-39.

21. Liang W, Wu L, Ling X, Schroder PM, Ju W, et al. Living donor liver transplantation versus deceased donor liver transplantation for hepatocellular carcinoma: a meta-analysis. Liver Transpl 2012;18:1226-36.

22. Fernandez-Sevilla E, Allard MA, Selten J, Golse N, Vibert E, et al. Recurrence of hepatocellular carcinoma after liver transplantation: Is there a place for resection? Liver Transpl 2017;23:440-7.

23. Sapisochin G, Goldaracena N, Astete S, Laurence JM, Davidson D, et al. Benefit of treating hepatocellular carcinoma recurrence after liver transplantation and analysis of prognostic factors for survival in a large Euro-American series. Ann Surg Oncol 2015;22:2286-94.

24. Kornberg A, Küpper B, Tannapfel A, Katenkamp K, Thrum K, et al. Long-term survival after recurrent hepatocellular carcinoma in liver transplant patients: clinical patterns and outcome variables. Eur J Surg Oncol 2010;36:275-80.

25. Valdivieso A, Bustamante J, Gastaca M, Uriarte JG, Ventoso A, et al. Management of hepatocellular carcinoma recurrence after liver transplantation. Transplant Proc 2010;42:660-2.

26. Escartin A, Sapisochin G, Bilbao I, Vilallonga R, Bueno J, et al. Recurrence of hepatocellular carcinoma after liver transplantation. Transplant Proc 2007;39:2308-10.

27. Kim HR, Cheon SH, Rha SY, Lee S, Han KH, et al. Treatment of recurrent hepatocellular carcinoma after liver transplantation. Asia Pac J Clin Oncol 2011;7:258-69.

28. Wang Y, Speeg KV, Washburn WK, Halff G. Sirolimus plus sorafenib in treating HCC recurrence after liver transplantation: a case report. World J Gastroenterol 2010;16:5518-22.

29. Bhoori S, Toffanin S, Sposito C, Germini A, Pellegrinelli A, et al. Personalized molecular targeted therapy in advanced, recurrent hepatocellular carcinoma after liver transplantation: a proof of principle. J Hepatol 2010;52:771-75.

30. Gomez-Martin C, Bustamante J, Castroagudin JF, Salcedo M, Garralda E, et al. Efficacy and safety of sorafenib in combination with mammalian target of rapamycin inhibitors for recurrent hepatocellular carcinoma after liver transplantation. Liver Transpl 2012;18:45-52.

31. Sposito C, Mariani L, Germini A, Reyes MF, Bongini M, et al. Comparative efficacy of sorafenib versus best supportive care in recurrent hepatocellular carcinoma after liver transplantation: a case-control study. J Hepatol 2013;59:59-66.

32. Weinmann A, Niederle IM, Koch S, Hoppe-Lotichius M, Heise M, et al. Sorafenib for recurrence of hepatocellular carcinoma after liver transplantation. Dig Liver Dis 2012;44:432-37.

33. Yoon DH, Ryoo BY, Ryu MH, Lee SG, Hwang S, et al. Sorafenib for recurrent hepatocellular carcinoma after liver transplantation. Jpn J 
Clin Oncol 2010;40:768-73.

34. Geissler EK, Schnitzbauer AA, Zülke C, Lamby PE, Proneth A, et al. Sirolimus use in liver transplant recipients with hepatocellular carcinoma: a randomized, multicenter, open- label phase 3 trial. Transplantation 2016;100:116-25.

35. Zhang ZH, Li LX, Li P, Lv SC, Pan B, et al. Sirolimus in liver transplant recipients with hepatocellular carcinoma: an updated metaanalysis. J Invest Surg 2019;32:632-41.

36. Jeng LB, Lee SG, Soin AS, Lee WC, Suh KS, et al. Efficacy and safety of everolimus with reduced tacrolimus in living-donor liver transplant recipients: 12-month results of a randomized multicenter study. Am J Transplant 2018;18:1435-46.

37. Cholongitas E, Mamou C, Rodríguez-Castro KI, Burra P. Mammalian target of rapamycin inhibitors are associated with lower rates of hepatocellular carcinoma recurrence after liver transplantation: a systematic review. Transpl Int 2014;27:1039-49.

38. Vivarelli M, Dazzi A, Zanello M, Cucchetti A, Cescon M, et al. Effect of different immunosuppressive schedules on recurrence-free survival after liver transplantation for hepatocellular carcinoma. Transplantation 2010;89:227-31.

39. Zhou J, Wang Z, Wu ZQ, Qiu SJ, Yu Y, et al. Sirolimus-based immunosuppression therapy in liver transplantation for patients with hepatocellular carcinoma exceeding the Milan criteria. Transplant Proc 2008;40:3548-53.

40. Iavarone M, Invernizzi F, Czauderna C, Sanduzzi-Zamparelli M, Bhoori S, et al. Preliminary experience on safety of regorafenib after sorafenib failure in recurrent hepatocellular carcinoma after liver transplantation. Am J Transplant 2019;19:3176-84.

41. Kittai AS, Oldham H, Cetnar J, Taylor M. Immune checkpoint inhibitors in organ transplant patients. J Immunother 2017;40:277-81.

42. Roayaie S, Schwartz JD, Sung MW, Emre SH, Miller C, et al. Recurrence of hepatocellular carcinoma after liver transplant: patterns and prognosis. Liver Transpl 2004;10:534-40.

43. Regalia E, Fassati LR, Valente U, Pulvirenti A, Damilano I, et al. Pattern and management of recurrent hepatocellular carcinoma after liver transplantation. J Hepatobiliary Pancreat Surg 1998;5:29-34.

44. Bodzin AS, Lunsford KE, Markovic D, Harlander-Locke MP, Busuttil RW, et al. Predicting mortality in patients developing recurrent hepatocellular carcinoma after liver transplantation: impact of treatment modality and recurrence characteristics. Ann Surg 2017;266:118-25.

45. Invenizzi F, Iavarone M, Donato MF, Mazzucco A, Torre M, et al. Pulmonary resection for metastasis of hepatocellular carcinoma recurring after liver transplant: an Italian multicenter experience. Front Oncol 2020;10:381.

46. Tomimaru Y, Sasaki Y, Yamada T, Eguchi H, Takami K, et al. The significance of surgical resection for pulmonary metastasis from hepatocellular carcinoma. Am J Surg 2006;192:46-51.

47. Bates MJ, Farkas E, Taylor D, McFadden PM. Pulmonary resection of metastatic hepatocellular carcinoma after liver transplantation. Ann Thorac Surg 2008;85:412-5.

48. Hwang S, Kim YH, Kim DK, Ahn CS, Moon DB, et al. Resection of pulmonary metastases from hepatocellular carcinoma following liver transplantation. World J Surg 2012;36:1592-602.

49. Nakajima J, Tanaka M, Matsumoto J, Takeuchi E, Fukami T, et al. Appraisal of surgical treatment for pulmonary metastasis from hepatocellular carcinoma. World J Surg 2005;29:715-8.

50. Poon RT, Fan ST, O'Suilleabhain CB, Wong J. Aggressive management of patients with extrahepatic and intrahepatic recurrences of hepatocellular carcinoma by combined resection and locoregional therapy. J Am Coll Surg 2002;195:311-8.

51. O'Suilleabhain CB, Poon RT, Lau CW, Fan ST. Repeated resections of extrahepatic metastases after hepatic resection: an aggressive approach to hepatocellular carcinoma. Hepatogastroenterology 2004;51:825-9.

52. Gwak GY, Jung JO, Sung SW, Lee HS. Long-term survival after pulmonary metastatectomy of hepatocellular carcinoma; treatment outcome or natural history? Hepatogastroenterology 2004;51:1428-33.

53. Han KN, Kim YT, Yoon JH, Suh KS, Song JY, et al. Role of surgical resection for pulmonary metastasis of hepatocellular carcinoma. Lung Cancer 2010;70:295-300.

54. Aoki M, Hatayama Y, Kawaguchi H, Hirose K, Sato M, et al. Stereotactic body radiotherapy for lung metastases as oligo-recurrence: a single institutional study. J Radiat Res 2016;57:55-61.

55. Zhai H, Liang P, Yu XL, Cheng Z, Han ZY, et al. Microwave ablation in treating intrahepatic recurrence of hepatocellular carcinoma after liver transplantation: an analysis of 11 cases. Int J Hyperthermia 2015;31:863-8.

56. Ko HK, Ko GY, Yoon HK, Sung KB. Tumor response to transcatheter arterial chemoembolization in recurrent hepatocellular carcinoma after living donor liver transplantation. Korean J Radiol 2007;8:320-7.

57. Rivera L, Giap H, Miller W, Fisher J, Hillebrand DJ, et al. Hepatic intra-arterial infusion of yttrium-90 microspheres in the treatment of recurrent hepatocellular carcinoma after liver transplantation: a case report. World J Gastroenterol 2006;12:5729-32.

58. Huang J, Yan L, Wu H, Yang J, Liao M, et al. Is radiofrequency ablation applicable for recurrent hepatocellular carcinoma after liver transplantation? J Surg Res 2016;200:122-30.

59. Zhou B, Shan H, Zhu KS, Jiang ZB, Guan SH, et al. Chemoembolization with lobaplatin mixed with iodized oil for unresectable recurrent hepatocellular carcinoma after orthotopic liver transplantation. J Vasc Interv Radiol 2010;21:333-8.

60. Toso C, Mentha G, Majno P. Integrating sorafenib into an algorithm for the management of post-transplant hepatocellular carcinoma recurrence. J Hepatol 2013;59:3-5.

61. Sanuki N, Takeda A, Kunieda E. Role of stereotactic body radiation therapy for hepatocellular carcinoma. World J Gastroenterol 2014;20:3100-11.

62. Sharabi AB, Nirschl CJ, Kochel CM, Nirschl TR, Francica BJ, et al. Stereotactic radiation therapy augments antigen-Specific PD-1mediated antitumor immune responses via cross-presentation of tumor antigen. Cancer Immunol Res 2015;3:345-55.

63. Parker JJ, Jones JC, Strober S, Knox SJ. Characterization of direct radiation-induced immune function and molecular signalling changes 
in an antigen presenting cell line. Clin Immunol 2013;148:44-55.

64. Gupta A, Probst HC, Vuong V, Landshammer A, Muth S, et al. Radiotherapy promotes tumor-specific effector CD8+ T cells via dendritic cell activation. J Immunol 2012;189:558-66.

65. Pfiffer TEF, Seehofer D, Nicolaou A, Neuhaus R, Riess H, et al. Recurrent hepatocellular carcinoma in liver transplant recipients: parameters affecting time to recurrence, treatment options and survival in the sorafenib era. Tumori 2011;97:436-41.

66. Roh YN, David Kwon CH, Song S, Shin M, Man Kim J, et al. The prognosis and treatment outcomes of patients with recurrent hepatocellular carcinoma after liver transplantation. Clin Transplant 2014;28:141-8.

67. Guerrini GP, Berretta M, Tarantino G, Magistri P, Pecchi A, et al. Multimodal oncological approach in patients affected by recurrent hepatocellular carcinoma after liver transplantation. Eur Rev Med Pharmacol Sci 2017;21:3421-35. 